\title{
Coupling bioturbation activity to metal (Fe and Mn) profiles in situ
}

\author{
L. R. Teal ${ }^{1,2, *}$, E. R. Parker $^{2}$, and M. Solan ${ }^{1, * *}$ \\ ${ }^{1}$ Oceanlab, University of Aberdeen, Newburgh, UK \\ ${ }^{2}$ Centre for Fisheries and Aquaculture Science (CEFAS), Lowestoft, UK \\ *now at: IMARES, Haringkade 1, 1976 CP Ijmuiden, the Netherlands \\ **now at: Ocean and Earth Science, National Oceanography Centre, University of Southampton, Waterfront Campus, \\ European Way, SO14 3ZH, Southampton, UK
}

Correspondence to: L. R. Teal (lorna.teal@wur.nl)

Received: 24 May 2012 - Published in Biogeosciences Discuss.: 17 July 2012

Revised: 6 February 2013 - Accepted: 15 March 2013 - Published: 10 April 2013

\begin{abstract}
The relative contributions that species assemblages, abiotic variables, and their interactions with one another make to ecosystem properties are recognised but are seldom considered simultaneously, within context, and at the appropriate spatio-temporal scales. Here, we combine fluorescent time-lapse sediment profile imaging (f-SPI) and diffusion gradient thin gels (DGT) to examine, in situ, the link between an important benthic ecosystem process (bioturbation) and the availability (profiles) of Fe and Mn. Whilst the combination of these methodologies (fg-SPI) was successful in gathering high-resolution in situ data of bioturbation activity and Fe/Mn profiles simultaneously, we show that the mechanistic basis of how the infaunal community mediate $\mathrm{Fe}$ and $\mathrm{Mn}$ is difficult to reconcile because of the spatiotemporal differences between particle and porewater mixing. This mismatch means that the consideration of these mechanistic processes in isolation is likely to limit our interpretative capacity of how infaunal communities mediate various biogeochemical processes in the natural environment. Moreover, the combination of multiple technologies, process based simulation modelling and generalised additive statistical modelling achieved here, emphasises the importance of simultaneously considering additional factors that influence benthic chemistry, in particular bioirrigation and tidal flushing of the sediment profile. Our findings highlight a pressing need to determine how the relative importance of multiple abiotic and biotic factors act in concert to alter major biogeochemical pathways across a variety of contexts and habitats.
\end{abstract}

\section{Introduction}

Anticipated future declines in marine species abundances and local biodiversity will have negative ecological consequences (Worm et al. 2006, Solan et al. 2004a) and attention is now turning to the prediction of ecosystem responses to human activity across a broad range of spatial scales (Halpern et al., 2008; Webb et al., 2009). Although highly controlled experiments have been instrumental in formulating a mechanistic understanding of how single (e.g. Duport et al., 2006; Stief and de Beer, 2006; Peterson et al., 2009) and multiple species (e.g. Emmerson et al., 2001; Marinelli and Williams, 2003; Ieno et al., 2006; Caliman et al. ,2007) influence a range of benthic ecosystem functions (Cardinale et al., 2006), it is known that these diversity-process-function relations are context dependent (e.g. Rossi et al., 2008) and modified by the environment (Bulling et al., 2010; Hicks et al., 2011). Single environmental variables, such as temperature (Ouelette et al., 2004), food availability (Nogaro et al., 2008; Maire et al., 2007), light (Rosenberg and Lundberg, 2004), $\mathrm{pH}$ (Widdicombe and Needham, 2007), and flow (Solan and Kennedy, 2002; Biles et al., 2002), can act alone, or in concert (Bulling et al., 2010), to modify species contributions to a variety of response variables (ecosystem functions). In natural systems, many of these processes will be further influenced in both time and space due to habitat heterogeneity (Zajac, 2001; Dyson et al., 2007; Bulling et al., 2008) and changes in the availability and distribution of resources (Godbold et al., 2011; Jamieson et al., 2011). These dynamics in the environment and organisms activities and responses are reflected in sediment biogeochemical processes 
(Chapman and Tolhurst, 2007; Teal et al., 2010; Gilbertson et al., 2012). The relative importance of organisms versus the environment in mediating associated sediment function (biogeochemical cycling) however, can be difficult to distinguish (Godbold and Solan, 2009). In situ observations and studies are therefore necessary to account for the context dependent effects of inter- and intra-specific behaviour, whilst also integrating species-environment interactions (Bulling et al., 2010; Hicks et al., 2011) when establishing a link between what organisms do and how the ecosystem processes and functions respond.

Here our aim was to gain a better understanding of the intricate link between bioturbation activity (an ecosystem process strongly influenced by species diversity) and the vertical distribution of metals ( $\mathrm{Fe}$ and $\mathrm{Mn}$ ) in the sediment. $\mathrm{Fe}$ and $\mathrm{Mn}$ are the two most abundant transition metals in natural environments, but most importantly $\mathrm{Fe}$ and $\mathrm{Mn}$ oxides and oxyhydroxides represent significant oxidants for organic carbon degradation (an important ecosystem function) in marine sediments (Aller, 1994; Thamdrup et al., 1994). Understanding how these oxidants are influenced by bioturbation can thus help bridge the gap in understanding the link between biodiversity, ecosystem process and ecosystem function. Reduction of iron and manganese oxides, in contrast to other reduction processes (e.g. using oxygen, nitrate or sulphate), uses solid rather than dissolved electron acceptors. Because of the particulate nature of $\mathrm{Mn}$ and $\mathrm{Fe}$ oxides, bioturbation is considered a particularly important regulator of $\mathrm{Mn}$ and $\mathrm{Fe}$ reduction (Thamdrup et al., 1994; Mouret et al., 2008). Infaunal activity is responsible for the downward movement of metal oxides into reduced sediment environments as well as the upward movement of reduced metal forms (e.g. pyrite) into the oxidised sediment environment. Bioturbation is thus the main reason why $\mathrm{Fe}$ and $\mathrm{Mn}$ undergo multiple oxidation and reduction cycles (Aller, 1990, 1994). Faunal respiration and bioturbation also mediate the oxygen and nitrogen cycles within muddy sediments, which in turn control the succession within the sediment of $\mathrm{Mn}$ and Fe reduction. These metals can therefore be closely linked to infaunal particle mixing, both from surface to depth and vice versa.

Trying to establish links between species diversity, ecosystem process (bioturbation) and ecosystem function (biogeochemical cycling) in a natural benthic system, however, is challenging, and despite the routine availability of technology (for review, see Solan et al., 2003) that can quantify particular ecosystem functions (e.g. trace metals, Fones et al., 2001; Teal et al., 2009; oxygen, Glud et al., 2001; pH and $p \mathrm{CO}_{2}$, Fan et al., 2011), ecosystem processes (e.g. bioturbation, Solan et al., 2004b; bioirrigation, Forster and Graf, 1995) or infaunal behaviour (Solan and Kennedy, 2002; Maire et al., 2010; Jamieson et al., 2011), inferences gained from each technology remain separate because multiple technologies are seldom used together (Solan et al., 2003; exceptions include: Teal et al., 2009; Fan et al., 2011, Stahl et al., 2012). High-resolution methods linking pore-water met- als and oxygen are only just becoming available in laboratory settings (Stahl et al., 2012; Zhu and Aller, 2012).

In this study we combine two available in situ methodologies (f-SPI, Solan et al., 2004b; g-SPI, Teal et al., 2009) to allow simultaneous acquisition of the necessary highresolution measurements of bioturbation (ecosystem process) and vertical metal ( $\mathrm{Fe}$ and $\mathrm{Mn}$ ) profiles within an environmental context. Measurements and quantification of bioturbation (i.e. particle mixing) are achieved with the sediment profile imaging (SPI) camera used in combination with fluorescent particles (luminophores) to track particle movement (Solan et al., 2004b) and allow modelling and quantification of infaunal activities (Schiffers et al., 2011). Fe and Mn profiles are derived from the diffusive gradients in thin film (DGT) gels, which can be mounted on a SPI lander (Teal et al., 2009). Whilst some limitations of the interpretation of DGT measurements must be taken into account (Davison et al., 1997; Fones et al., 2001, Stockdale et al., 2009), the benefits of the DGT technique are the concentration of metals into a detectable range at an appropriate resolution and the feasibility of using the gels in situ on a lander (Fones et al. 2001; Teal et al., 2009). Furthermore, oxidised sediments are coloured reddish-brown by the presence of $\mathrm{FeOOH}$ (oxidised, particulate Fe; Lyle 1983) and grey where Mn is reduced (Jakobsson et al., 2000). These sediment colour changes linked to metal redox make the combination of highresolution DGT and SPI (which also used sediment colour) useful for a stronger interpretation of sediment colour and metal profiles (Teal et al., 2009) and can further our understanding of the linkage between particle mixing as a result of bioturbation and $\mathrm{Mn} / \mathrm{Fe}$ cycles. This is in contrast to cycles of other terminal electron acceptors (TEAs) such as oxygen, nitrate and sulphate which are dissolved chemical species and so controlled either by molecular diffusion or bio-irrigation processes to a greater extent. The simultaneously collected high-resolution data is used to test whether the concurrent use of multiple technologies, when examined with analytical techniques that allow a better mechanistic understanding at the appropriate spatio-temporal scale (simulation models, Schiffers et al., 2011; general additive modelling) provide additional insights into the coupling between an bioturbation and metal (Fe and $\mathrm{Mn}$ ) profiles.

\section{Materials and methods}

\subsection{Sediment profile imaging with DGT and fluorescent particle detection}

A sediment profile imaging (SPI) camera, incorporating two diffusive gradient in thin film (DGT) gels (each $18.5 \times 2 \times 0.1 \mathrm{~cm}$ ) within the faceplate (for measuring trace metal profiles, g-SPI; Teal et al., 2009) was optically modified to allow preferential imaging of fluorescent sediment particles (f-SPI; Solan et al., 2004b; Schiffers et al., 2011). 
The dimensions of the fg-SPI faceplate were $15 \times 21.5 \mathrm{~cm}$ $\left(=322.50 \mathrm{~cm}^{2}\right)$, but after subtraction of the area occupied by the two DGT gels the field of view reduces to $8.4 \times 21.5 \mathrm{~cm}$ $\left(=180.6 \mathrm{~cm}^{2}\right)$. The camera (Nikon D100, $2000 \times 3000$ pixels $=6$ mega pixels, effective resolution $=75 \times 75 \mu \mathrm{m}$ per pixel) was set to an exposure of $1 / 60, f=2.0$ and film speed equivalent to ISO 400 . The filter, resin gel and diffusive gel needed to make up the DGT sandwich for the detection of trace metals ( $\mathrm{Fe}$ and $\mathrm{Mn}$ ) were purchased from DGT Research Ltd (http://www.dgtresearch.com) and prepared following the methodology of Teal et al. (2009). A maximum area $1 \times 17.5 \mathrm{~cm} \mathrm{gel}^{-1}(n=2)$ is exposed to the sediment during deployment, depending on the depth of fg-SPI prism penetration.

Once deployed, dissolved $(<0.45 \mu \mathrm{m})$ metal species are able to diffuse into the DGT device via the exposure window and after traversing the diffusive gel layer metal ions that come in contact with the Chelex-100 (resin gel layer) become bound and permanently immobilised. Assuming the metal ions bind quickly and efficiently to the resin gel, the concentration of metals at the resin-diffusion gel interface effectively remains as zero, resulting in the formation of a linear concentration gradient across the diffusive layer and hence continuous metal uptake until the resin reaches saturation (Zhang and Davison, 1995). DGT was preferred over the use of Diffusive Equilibrium in thin film (DET) gels (Davison et al., 2000) as it pre-concentrates metals which improves detection levels and also the continuous uptake of the DGT gel in effect provides a trace metal profile that reflects porewater profiles over the full length of the deployment, thus giving a sum of the processes occurring during this time. In contrast, DET gels are continuously equilibrating with their environment and would only reflect profiles during the end of the deployment, but more importantly trace metals may also be lost from the gel as the SPI camera is retrieved at the end of deployments and ascends through the water column.

Three replicate time-lapse deployments of the fg-SPI were carried out within a $50 \mathrm{~m}$ radius in Loch Creran, West Scotland (centred around $56^{\circ} 31.66^{\prime} \mathrm{N}, 5^{\circ} 21.11^{\prime} \mathrm{W}$ ), during JuneJuly 2008. The fg-SPI was detached from the research vessel and, to prevent any wind or tidal mediated drag affecting the camera position, the surface buoy was attached to a drop anchor. For each time-lapse sequence, images were taken every $5 \mathrm{~min}$ for a period of $96 \mathrm{~h}(n=1152$ images per deployment). Luminophores (125-150 $\mu \mathrm{m}, \sim 30 \mathrm{~g}$ dry weight) were manually spread in front of the SPI faceplate by a SCUBA diver immediately after the camera was deployed (see Supplement Fig. S1a). As high spatial variability in the trace metal profiles was anticipated (Teal et al., 2009), three additional DGT probes (area of gel $=1.8 \times 15 \mathrm{~cm}=27 \mathrm{~cm}^{2}$ ) were inserted into the sediment profile to a depth of $11 \mathrm{~cm}$ by SCUBA divers within the immediate vicinity $(<1 \mathrm{~m})$ of the fg-SPI faceplate (see Supplement Fig. S1b). The DGT probes were stored in sealed Ziploc ${ }^{\circledR}$ plastic bags at $4{ }^{\circ} \mathrm{C} \pm 1{ }^{\circ} \mathrm{C}$ prior to deployment and were attached to the fg-SPI frame using a custom-made PVC holder.

As infaunal activity is known to be influenced by environmental factors, such as flow (Biles et al., 2002) and temperature (Ouelette et al., 2004), a CTD (Saiv A/S STD/CTD, model SD204) and current meter were attached to the fg-SPI to monitor current speed, temperature and the tidal cycle (every $20 \mathrm{~s}$ ) for the duration of each deployment.

\subsection{Site characteristics}

The sediment was characterised using an unmodified sediment profile imaging (SPI) camera (for general principles, see Rhoads and Cande, 1971; usage in benthic characterisation reviewed in Germano et al., 2011) to obtain in situ images $\left(15 \times 21.5 \mathrm{~cm}=322.50 \mathrm{~cm}^{2}\right)$ of the sediment profile to derive an image-based mixing depth $\left(\mathrm{MD}_{\mathrm{I}}\right.$, Teal et al., 2010). The imaging module is based around a Nikon D100 camera $(2000 \times 3000$ pixels $=6$ mega pixels, effective resolution $=75 \times 75 \mu \mathrm{m}$ per pixel), set to an exposure of $1 / 60$ and a film speed equivalent to ISO 400 . A total of 20 images within a $50 \mathrm{~m}$ radius of the sample station were obtained.

The depth of the vertical colour transition (from brown to olive green/black, Lyle, 1983) was delineated using standard threshold analysis of 8-bit (greyscale) tagged image file format (TIFF) images. The upper limit of the region of interest was delineated by the sediment-water interface, whilst the lower limit of the region of interest was determined by using the most appropriate threshold level (user defined) that distinguished the oxidised sediment (high reflectance) from the underlying reduced sediment (low reflectance). The image derived mixing depth $\left(\mathrm{MD}_{\mathrm{I}}\right)$ is defined as the mean vertical distance of the sediment area that has grey scale intensities above the user-defined threshold value. All image analysis was performed using a custom-made, semi-automated macro (modified from Solan et al., 2004b) within ImageJ (version 1.40), a Java-based public domain program developed at the USA National Institutes of Health (available at: http://rsb.info.nih.gov/ij/index.html).

To characterise the indicative infaunal community present at the site, macrofauna were identified from the returns of 6 grabs (area sampled per grab $=314 \mathrm{~cm}^{2}$, depth $\sim 10 \mathrm{~cm}$, sieved on a $1 \mathrm{~mm}$ mesh) taken from within $50 \mathrm{~m}$ of the fgSPI. Fauna were stored in a solution of $4 \%$ formaldehyde buffered with seawater (salinity, 33) and identified to species $(75 \%)$ or family $(25 \%)$ level. Biomass ( $g$ wet weight) was determined to 5 decimal places using an Ohaus Adventurer Pro balance. All fauna were blotted dry with absorbent paper to remove any excess liquid prior to weighing.

\subsection{DGT analysis}

All DGT sample preparation was undertaken in a laminar flow cabinet (BassAire - Class100). The top membrane and diffusive gel layer were discarded and the resin gel layer 
was sliced at $2 \mathrm{~mm}$ resolution using a Teflon coated stainless steel razor blade. Each gel slice was eluted with $2 \mathrm{~mol} \mathrm{~L}^{-1}$ $\mathrm{HNO}_{3}(100 \mu \mathrm{L})$ for $24 \mathrm{~h}$ and then diluted $(75 \mu \mathrm{L}$ sample: $925 \mu \mathrm{L} 2 \mathrm{~mol} \mathrm{~L}^{-1} \mathrm{HNO}_{3}$ ). Where, $2 \mathrm{~mol} \mathrm{~L}^{-1} \mathrm{HNO}_{3}$ releases $80 \%( \pm 4 \%)$ of the metal bound to the Chelex (Zhang et al., 1995). The solutions were analysed for two trace metals (Fe, Mn) using an Agilent Technologies 7500ce Inductively Coupled Plasma - Mass Spectrometer (ICP-MS). The ICP-MS has an octopole reaction system to remove spectral interferences. Fe was analysed in reaction mode $\left(\mathrm{H}_{2}\right)$ and $\mathrm{Mn}$, in collision mode (He), to remove all the polyatomic spectral interferences. The ICP-MS was calibrated every day prior to the analysis of samples using dilutions (0$\left.200 \mathrm{\mu g} \mathrm{kg}^{-1}\right)$ of a mixed stock standard $\left(100 \mathrm{mg} \mathrm{kg}^{-1}\right)$. An internal standard of $\mathrm{Rh}^{103}\left(50 \mu \mathrm{g} \mathrm{kg}^{-1}\right)$ was used to check for drift of the machine during the day and a certified reference material (SLRS-4) was used to check the calibrations and recovery of the ICP-MS.

Assuming a seawater density of $1 \mathrm{~g} \mathrm{~mL}^{-1}$, the measured concentrations, $C_{g}\left(\mu \mathrm{g} \mathrm{kg}^{-1}\right)$ of the DGT gel solutions were converted to molar concentrations and used to calculate the mass, $M\left(\mathrm{nmol} \mathrm{cm}{ }^{-2}\right)$, accumulated in the resin layer of each gel strip:

$M=\left(\frac{C_{g} v+V}{0.8 \times A}\right) \frac{1}{x}$,

where $V$ is the volume of gel $(\mathrm{mL}), v$ the extractant volume $(\mathrm{mL})$ and $x$ the atomic mass of the element in question. The factor 0.8 accounts for the fact that only $80 \%$ of the bound metal ( $\mathrm{Fe}$ and $\mathrm{Mn}$ ) is released. Knowing the time of gel deployment, $t(\mathrm{~s})$, allowed calculation of the time averaged Flux $F\left(\mathrm{nmol} \mathrm{cm}{ }^{-2} \mathrm{~s}^{-1}\right)$ of metal from the porewaters to the resin strip:

$F=\frac{M}{t \times A}$,

where $A$ is the area of exposed gel $\left(\mathrm{cm}^{2}\right)$. The term "flux" used from here onwards thus refers to the flux of reduced $\mathrm{Fe}$ and $\mathrm{Mn}$ forms from the pore water to the resin gel of the DGT (i.e. not reduction fluxes or process rates) and serves as a proxy for $\mathrm{Fe}$ and $\mathrm{Mn}$ availability.

\subsection{Image analysis of fluorescent sediment particles}

Images were saved in red-green-blue (RGB) colour with JPEG (Joint Photographic Experts Group) compression and analysed using a custom-made, semi-automated macro (Solan et al., 2004b) within ImageJ (version 1.40). The user manually draws in the sediment-water interface on each image and selects an appropriate threshold to select all luminophores. As the primary interest is the vertical distribution of particles relative to the sediment water interface, it is important that depth is measured relative to the sedimentwater interface. Therefore, the macro returns a binary ma- trix $(0=$ sediment, $1=$ luminophores $)$ using the sedimentwater interface as the uppermost horizontal row. The total luminophores in each pixel row are then summed to provide the vertical profile of luminophores.

\subsection{Statistical analysis}

In contrast to previous qualitative methods (e.g. Lesven et al., 2008), a general additive model (GAM, Wood, 2006) was used to determine underlying patterns in the shape of the replicate $\mathrm{Fe}$ and $\mathrm{Mn}$ profiles for each deployment. This method is preferential because differences in the shape of replicate profiles and the depth of trace metal flux peaks are of interest, rather than the absolute flux values. GAMs use smoothing curves to model non-linear relationships between the response variable ( $\mathrm{Fe}$ or Mn flux) and the explanatory variable (depth). Following Wood (2006), thin plate smoothing splines were used to model the non-linearity and the smoothing parameter estimation (degrees of freedom) was optimised using a generalised cross validation procedure. In total, six GAMs were fitted, one for each trace metal $(\mathrm{Fe}$ and $\mathrm{Mn})$ across all deployments $(n=3)$. Whilst it can be expected that the heterogeneity between trace metal profiles is large enough for single smoothers to be fitted to each individual profile (Teal et al., 2009), our objective is to establish whether an underlying trend may link directly to infaunal activity levels. Hence, only one smoother was fitted with depth for each GAM, rather than modelling the full heterogeneity in flux patterns using multiple smoothers. Both $\mathrm{Fe}$ and $\mathrm{Mn}$ flux were cube-root transformed to reduce the influence of peaks in absolute values on the underlying smoother trends. Profile identity (hereafter, profile ID) was fitted as a nominal variable to account for differences in absolute flux values between replicates. All models were validated by visual comparison of residual plots and final models were used to predict $\mathrm{Fe}$ and Mn flux profiles with depth for each deployment. These predicted profiles were then compared to observed vertical distributions of bioturbation activity (luminophore profiles).

\subsection{Bioturbation model}

Luminophore profiles obtained from hourly images $(n=94$ per deployment) in the fg-SPI sequences were analysed using a process based simulation model (Schiffers et al., 2011). The output parameters of the simulation model, activity, tracer.dif, and distance, describe the mechanistics of the observed particle displacement (activity $=$ the probability that a luminophore pixel will be displaced between two timesteps; distance $=$ the mean distance of the particle displacement between each time step; and tracer.dif is used as a weighting parameter to account for any differences in specific density between the luminophore tracer and the sediment that may change the probability of passive tracer displacement (Schiffers et al., 2011). Use of the simulation model is 


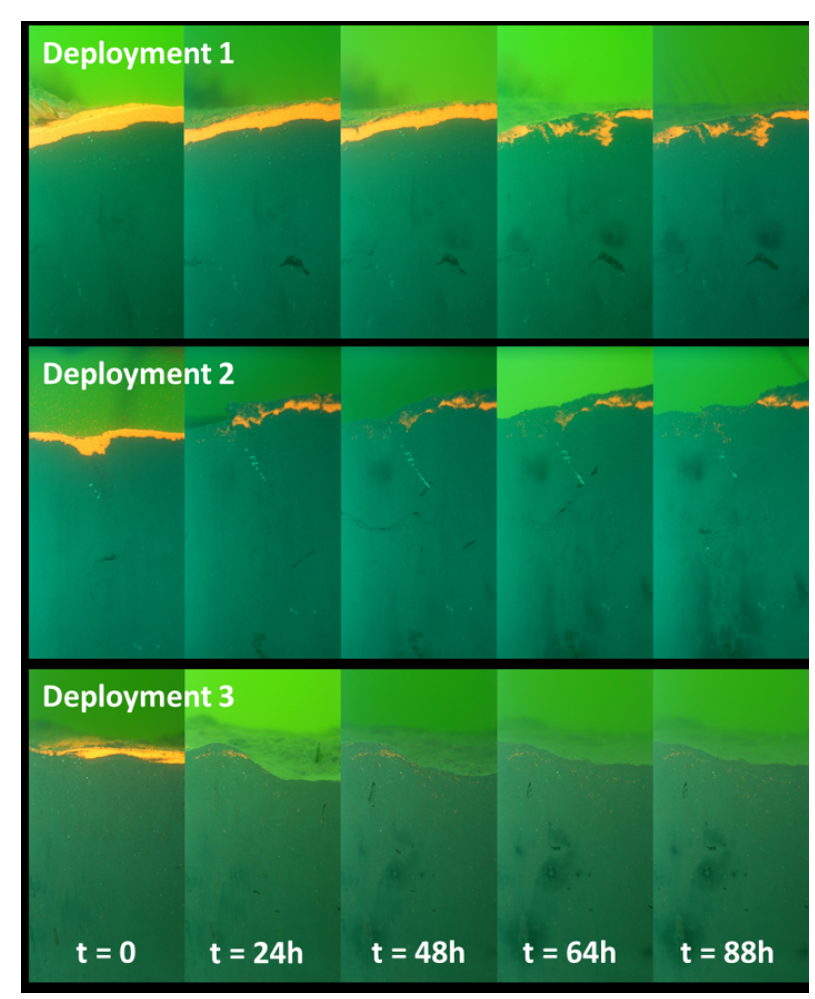

Fig. 1. Selected images from the SPI time-lapse sequence detailing the impact of bioturbation on luminophore particle displacement during the three separate deployments showing a frame for each $24 \mathrm{~h}$ period starting from frame $1(t=0 \mathrm{~min})$. Luminophore particles appear as orange against the sediment in dark green. Scale: frame width $=7 \mathrm{~cm}$.

preferential to other ways of interpreting tracer profiles, such as the calculation of bioturbation coefficients (see review by Meysman et al., 2008), because the short duration of the experiment ( 5 days) means that the underlying assumptions behind the calculation of bioturbation coefficients are violated. Following Schiffers et al. (2011), a sensitivity analysis was first performed to test for possible correlations between the parameters activity and distance,. The optimal combination of parameter values, i.e. where the sum of squares reached a minimum, were then identified using the "optim" function implemented in the "R" statistical and programming environment (R Development Core Team, 2008). The final fitting procedure was repeated 5 times to obtain mean parameter estimates and corresponding error estimation.

\section{Results}

\subsection{Loch Creran site characteristics and faunal assemblage}

Loch Creran is a sheltered loch, and sea state was comparable (calm) for all three deployments. Temperatures and salinities showed a mean $( \pm \mathrm{SD})$ of $12.12 \pm 0.13^{\circ} \mathrm{C}$ and $33.57 \pm 0.06$, respectively, during deployment $1,12.35 \pm 0.07^{\circ} \mathrm{C}$ and $33.39 \pm 0.13$ during deployment 2 and $12.45 \pm 0.08^{\circ} \mathrm{C}$ and $33.53 \pm 0.12$ during deployment 3 . All deployments were carried out at $13 \mathrm{~m}$ water depth, but the tidal influence meant that the depth ranged from 11.7-13.9 $\mathrm{m}$ during deployment 1, from 11.2-14.6m during deployment 2 and from 11.3$14.5 \mathrm{~m}$ during deployment 3 . Tides of this extent are not expected to influence pore-water flow but can affect the behaviour of infauna. The sediments at the station are characterised by a mean sediment grain size of $79.28 \pm 4.4 \mu \mathrm{m}$ and a mean total organic matter content of $6.7 \pm 1.5 \%(n=5$ in both cases, matching station 7 described in Godbold and Solan, 2009). The topography of the sediment is fairly homogenous with biogenic mounds, tracks and burrows visible (see Supplement Figs. S1 and S2). Based on our observations, the dominant process affecting the sediment during the deployments is bioturbation.

The SPI survey of the site $(n=20)$ immediately prior to the fg-SPI deployments, revealed a mean $( \pm \mathrm{SD})$ sediment mixing depth $\left(\mathrm{MD}_{\mathrm{I}}\right)$ of $3.7 \pm 0.9 \mathrm{~cm}(n=20$, range $=2.6-$ $5.9 \mathrm{~cm}$ ). Infaunal burrows were consistently present, showing evidence of high bioturbation activity and considerable spatial heterogeneity of the sediment environment. The faunal returns indicated a species rich community characterised by high abundances of the bivalve Abra nitida and to a slightly lesser extent Amphiura chiajei (brittle star), Terrebellidae spp. and Scalibragma inflatum (both Polychaete worms, Table 1). Turritella communis and A. chiajei were the biomass dominants followed closely by A. nitida and Terrebellidae sp. 1 and the Capitellids Heteromastus filiformis and Notomastus latericeus (Table 1). Although T. communis was only found in 2 of 6 samples, evidence from SCUBA diver photography (Fig. S2) indicated that this species was present in high abundance at the site.

\subsection{Particle bioturbation}

The time lapse f-SPI sequences (all sequences are available online, see link in acknowledgements) showed considerable variability between deployments (Figs. 1 and 2), reflecting temporal differences in species composition and species behaviour during the sequence. In deployment 1 (Fig. 2a) the initial surficial layer of luminophores remained largely undisturbed for an extended period of time $(\sim 60 \mathrm{~h})$, although a small downward movement most likely related to the upward extension of Amphiura spp. (based on Table 1, most likely Amphiura chiajei) feeding 'arms' was observed. An immediate change in luminophore distribution occurs at $\sim 3800 \mathrm{~min}(60 \mathrm{~h})$, following the appearance of a decapod Crustacean (most likely Carcinus maenas) that mixes sediment to a depth $>2 \mathrm{~cm}$. Consistent with the findings of Solan et al. (2004b), this event masks the effect of Amphiura spp., which were active throughout the time-lapse sequence. 
Table 1. Summary of mean species abundance $(\mathrm{A} \pm \mathrm{SD})$ and biomass $(\mathrm{B}, g \pm \mathrm{SD})$ per $\mathrm{m}^{2}$ at the Loch Creran sampling site. $N$ shows the total number of samples where each species was present $\left(N_{\text {total }}=6\right), \mathrm{BP}_{\mathrm{i}}$ is the bioturbation index of each species and $\mathrm{BP}_{\mathrm{p}}$ the bioturbation potential of the species taking into account abundance (following Solan et al., 2004b).

\begin{tabular}{llrrrrrrr}
\hline Species & Phylum & $\mathrm{A}$ & $\pm \mathrm{SD}$ & $\mathrm{B}$ & $\pm \mathrm{SD}$ & $N$ & $\mathrm{BP}_{\mathrm{i}}$ & $\mathrm{BP}_{\mathrm{p}}$ \\
\hline Abra nitida & Mollusca & 132.63 & 6.03 & 0.5181 & 1.2956 & 3 & 2.88 & 381.86 \\
Amphipoda & Arthropoda & 5.31 & - & 0.0078 & - & 1 & 1.06 & 5.63 \\
Amphiura chiajei & Echinodermata & 42.44 & 36.75 & 6.9845 & 6.8296 & 4 & 31.71 & 1345.94 \\
Capitellidae sp. & Annelida & 5.31 & - & 0.0179 & - & 1 & 0.80 & 4.26 \\
Corbula gibba & Mollusca & 5.31 & - & 0.0477 & - & 1 & 1.75 & 9.28 \\
Cylichna cylindracea & Mollusca & 10.61 & 0.00 & 0.0452 & 0.0099 & 2 & 2.55 & 27.07 \\
Euclymene robusta & Annelida & 10.61 & - & 0.1846 & - & 1 & 2.58 & 27.35 \\
Eumida sanguinea & Annelida & 5.31 & - & 0.0025 & - & 1 & 0.60 & 3.19 \\
Heteromastus filiformis & Annelida & 15.92 & 22.51 & 0.2553 & 0.5204 & 2 & 1.52 & 24.13 \\
Magelona mirabilis & Annelida & 5.31 & - & 0.0001 & - & 1 & 0.06 & 0.32 \\
Maldane sarsi & Annelida & 5.31 & - & 0.0204 & - & 1 & 0.29 & 1.52 \\
Notomastus latericeus & Annelida & 10.61 & 0.00 & 0.3021 & 0.6808 & 2 & 6.60 & 69.98 \\
Nucula nitidosa & Mollusca & 10.61 & 0.00 & 0.0838 & 0.1621 & 2 & 2.32 & 24.57 \\
Odostomia sp. & Mollusca & 10.61 & - & 0.0075 & - & 1 & 0.17 & 1.84 \\
Phyllodocidae sp. & Annelida & 5.31 & - & - & - & 1 & $\mathrm{NA}$ & $\mathrm{NA}$ \\
Polychaete fragments & Annelida & - & - & 0.1446 & - & 1 & $\mathrm{NA}$ & $\mathrm{NA}$ \\
Sabellidae & Annelida & 10.61 & - & 0.1407 & - & 1 & 1.13 & 11.94 \\
Scalibregma inflatum & Annelida & 26.52 & 36.75 & 0.0879 & 0.2456 & 3 & 3.56 & 94.35 \\
Terrebellidae sp. 1 & Annelida & 37.14 & 36.75 & 0.5797 & 1.3027 & 2 & 2.28 & 84.83 \\
Terrebellidae sp. 2 & Annelida & 10.61 & - & 0.0075 & - & 1 & 0.17 & 1.84 \\
Thracia pubescens & Mollusca & 5.31 & - & 0.3728 & - & 1 & 4.88 & 25.94 \\
Turritella communis & Mollusca & 15.92 & 0.71 & 13.2635 & 53.4996 & 2 & 43.70 & 695.75 \\
\hline & & & & & & & \\
\hline & & & & & & &
\end{tabular}

In deployment 2, particle mixing to 1.5 to $2 \mathrm{~cm}$ occurs more rapidly than during deployment 1 and an initial subduction of luminophores is evident at $\sim 600 \mathrm{~min}(10 \mathrm{~h})$ following feeding activity by one individual of Turritella communis (Fig.s 1 and $2 b$ ). A further downward injection of luminophores is evident at $\sim 1500 \mathrm{~min}(25 \mathrm{~h}$, Fig. $2 \mathrm{~b}$ ), which is related to the presence of a decapod crustacean (most likely Carcinus maenas) and other epifauna (e.g. Asterias rubens, Crangon sp. and a Gobiidae species). Burrowing at depths below the level of luminophore incorporation $(>5 \mathrm{~cm})$ also occurred, although it was not possible to confirm which species were active at these depths.

The greatest redistribution of luminophores occurred during deployment 3 (Fig. 2c). The most striking bioturbation events occurred at $\sim 560 \mathrm{~min}(9.3 \mathrm{~h}), \sim 1000 \mathrm{~min}(16.7 \mathrm{~h})$ and $\sim 3000 \mathrm{~min}$ (50 h, Fig. 2c). Closer examination of the image sequence reveals that these events were associated with decapod crustacean activity, including burrowing activity ( $\sim 2 \mathrm{~cm}$ deep) at an elapsed deployment time of $1000 \mathrm{~min}$. Nevertheless, there was considerable redistribution of luminophores occurring within the sediment profile (Fig. 2c), largely associated with the burrowing and feeding behaviour of Amphiura spp. (based on Table 1 most likely Amphiura chiajei) and Nereidae spp..

The sensitivity analysis indicated a strong correlation between the bioturbation parameters activity and distance for all deployments (Fig. S3a-c), indicating that there was not a unique global minimum in parameter space, i.e. a wide range of value combinations ranging from low values for activity and high values for distance, to high values of activity and low values for distance were similarly plausible. However, as this preliminary optimisation indicated the optimal value for the parameter activity $(=0.99$, deployment $1 ; 0.91$, deployment $2 ; 0.98$, deployment 3 ), activity was fixed at these respective values (following Schiffers et al. 2011) to aid the appropriate optimisation of the values for tracer.dif and distance. The high values ( $>0.9$ ) of activity for all three deployments indicates the presence of continuous mixing. Model simulations showed acceptable levels of fit (Fig. S4) and parameter estimations showing very low variability (Table 2). The mean distance of particle displacement was $75 \pm 1 \mu \mathrm{m} \mathrm{h}^{-1}$ (deployment 1), $181 \pm 9 \mu \mathrm{m} \mathrm{h}^{-1}$ (deployment 2) and $390 \pm 43 \mu \mathrm{m} \mathrm{h}^{-1}$ (deployment 3). It is important to emphasise that these are not net downward movements but the average of both upward and downward movements across the time period of observation. Values for tracer.dif were similar during deployment $2(0.901 \pm 0.037)$ and deployment $3(0.958 \pm 0.062)$, but significantly larger than both these deployments $(t$ test, $p<0.001)$ during deployment $1(0.790 \pm 0.007)$, indicating some variation in tracer behaviour relative to sediment particles. 
Table 2. Summary of the replicate $(n=5)$ runs of the BFGS fitting procedure for each fg-SPI deployment for the estimated parameters distance and tracer.dif. As a preliminary optimisation revealed a strong correlation between activity and distance, activity was fixed as indicated for each deployment.

\begin{tabular}{rrrrr}
\hline Depl & activity & Run & distance & tracer.dif \\
\hline & & 1 & 75.40 & 0.7898 \\
& & 2 & 75.40 & 0.7846 \\
& 0.9903 & 3 & 75.28 & 0.7741 \\
& & 4 & 75.16 & 0.7898 \\
& & 5 & 75.48 & 0.7909 \\
\hline & & 1 & 180.71 & 0.9010 \\
$\mathbf{2}$ & 0.9118 & 3 & 179.64 & 0.9292 \\
& & 4 & 193.50 & 0.9778 \\
& & 5 & 202.81 & 0.9669 \\
\hline & & 1 & 409.72 & 0.9515 \\
& & 2 & 409.69 & 0.9952 \\
$\mathbf{3}$ & 0.9823 & 3 & 408.74 & 0.9969 \\
& & 4 & 313.50 & 0.8519 \\
& & 5 & 409.65 & 0.9952 \\
\hline
\end{tabular}

\subsection{Distribution of Fe and Mn}

The absolute flux values (supply rate of metal to the gel) and the depth of the profile peaks varied greatly for both Fe and Mn between deployments as well as between replicate profiles within the same deployment (Fig. 3a-f). Nevertheless, it was possible to establish underlying trends in the distribution of peaks between profiles within each deployment. Following the sequential utilisation of electron acceptors, Mn peaks are observed at shallower depths $(\sim 1-4 \mathrm{~cm})$ relative to the $\mathrm{Fe}$ peaks $(\sim 4-8 \mathrm{~cm})$ and both metals decrease in concentration below their respective peaks. The variability between profiles is most pronounced around the main subsurface peaks, indicating considerable heterogeneity (at the $\mu \mathrm{m}$ scale) within the sediment leading to variable depths $(2-10 \mathrm{~cm})$ of peak trace metal release into pore waters.

\subsection{Linking trace metal profiles and bioturbation}

All six GAMs fitted to Fe and Mn profiles of each deployment showed significant smoothers $(p<0.01$ in all cases, $\mathrm{d} f=3$ in all cases except for $\mathrm{Fe}$ deployment 2 , where $\mathrm{d} f=4)$ as well as a significant difference between replicates ( $p<0.01$ in all cases), indicating that absolute flux values differed significantly between replicate locations. Despite the difference in absolute values, it was possible to detect an underlying trend (smoother) in the shape of the profiles for each deployment and each metal. Based on the output, flux values $( \pm \mathrm{SD})$ of both Fe and Mn could be calculated to compare with luminophore distributions.
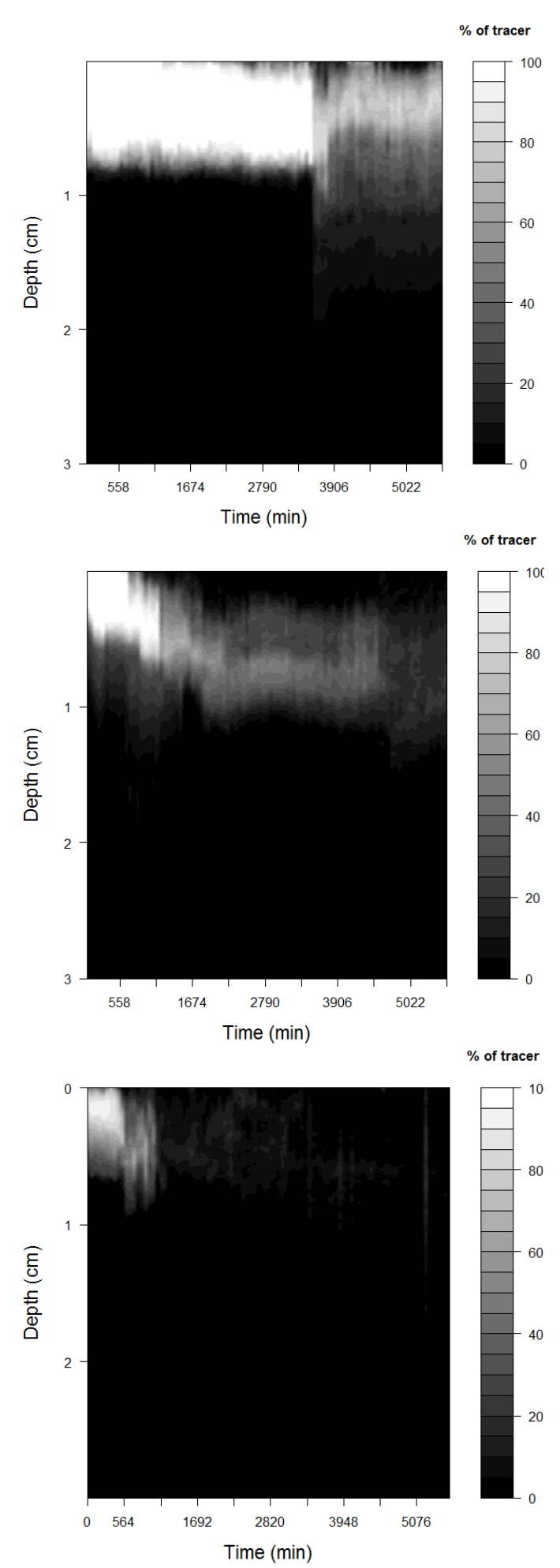

Fig. 2. The redistribution of luminophore particle tracers over time for (a) deployment 1, (b) deployment 2 and (c) deployment 3 of the fg-SPI. Luminophore counts are expressed relative to the total recovered from each image (\%) and represented by grey scale shading. 

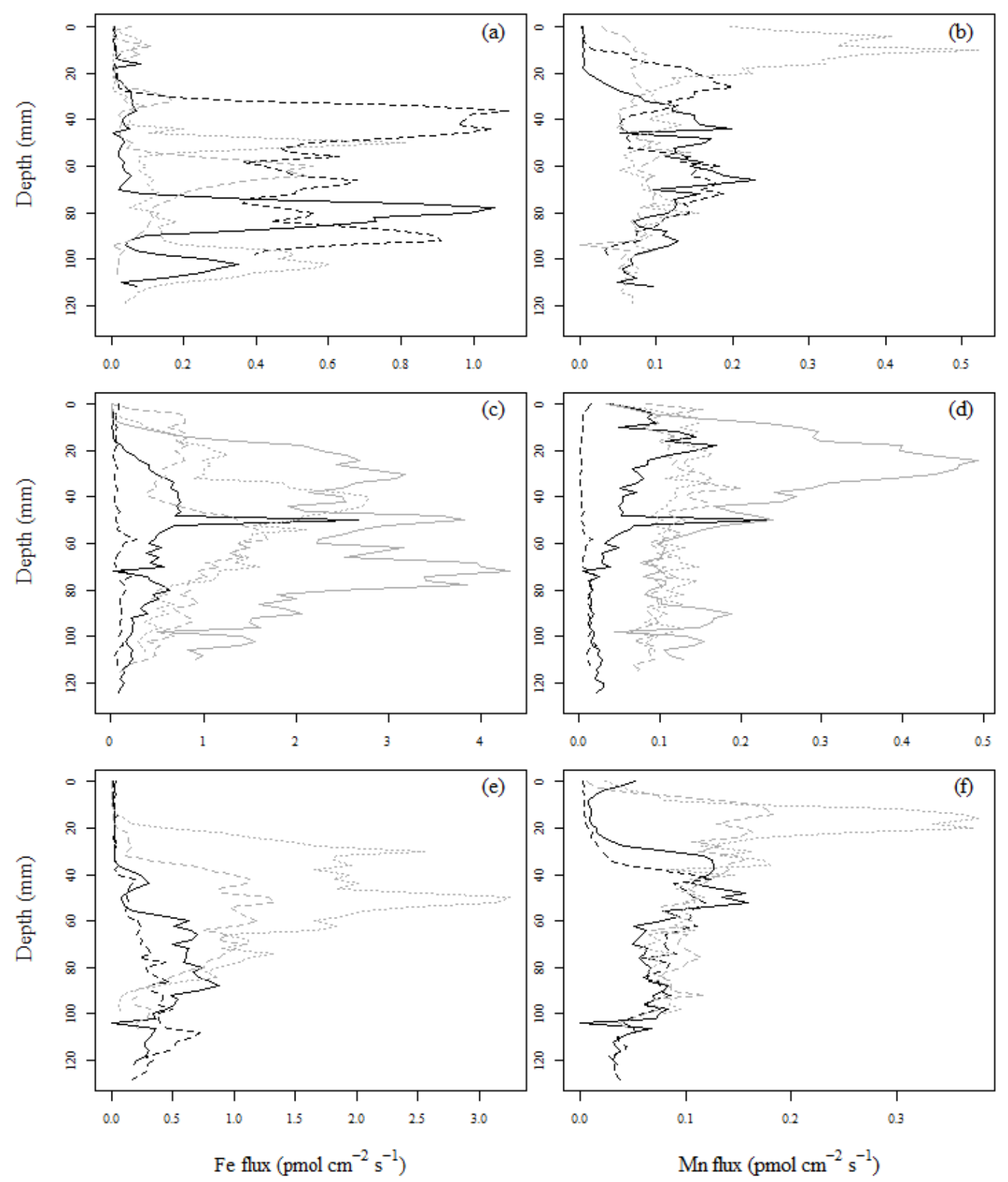

Fig. 3. Sediment profiles of trace metal flux for Fe (a), (c), (e) and Mn (b), (d), (f) for deployments 1 (a), (b), 2 (c), (d) and 3 (e), (f) of the fg-SPI. Solid lines denote profiles obtained from g-SPI gels (black $=$ left, grey $=$ right) and dashed lines denote profiles obtained from SCUBA diver-deployed gel probes ( $n=3$, except $n=2$ for Fe in deployment 1 and for Mn in deployment 2).

Predicted Fe and Mn flux profiles with sediment depth based on GAM show a gradual increase in fluxes at the sediment surface with flattened peaks at mid-depths (between 2-8 cm), gradually decreasing with depth (Fig. 4). Although the curves do not reveal any distinct depth-specific peaks in either $\mathrm{Fe}$ or $\mathrm{Mn}$, it is evident that $\mathrm{Fe}$ reaches maximal concentrations between 4-8 cm (Fig. 4a, c, e), and that Mn reaches maximal concentrations between $1-4 \mathrm{~cm}$ (Fig. $4 \mathrm{~b}, \mathrm{~d}, \mathrm{f}$ ). This pattern is consistent with a priori predictions based on biogeochemical zonation theory, i.e. as an electron acceptor, $\mathrm{Mn}>\mathrm{Fe}$ (Aller,
1982). The flattened shape of the curves and lack of a distinct peak for $\mathrm{Fe}$ and $\mathrm{Mn}$ reflect the variability in peaks between profiles, as well as the heterogeneity within profiles, which are averaged in the GAM analysis.

It is important to consider the shape of the $\mathrm{Fe}$ and $\mathrm{Mn}$ profiles in relation to the vertical distribution of luminophores. Over the time-period of observation, the luminophore profile remains limited to the upper $2 \mathrm{~cm}$ of the sediment profile, consistent with the depth region of Mn release (Fig. 4). The "noise" and slightly deeper penetration of luminophores in 

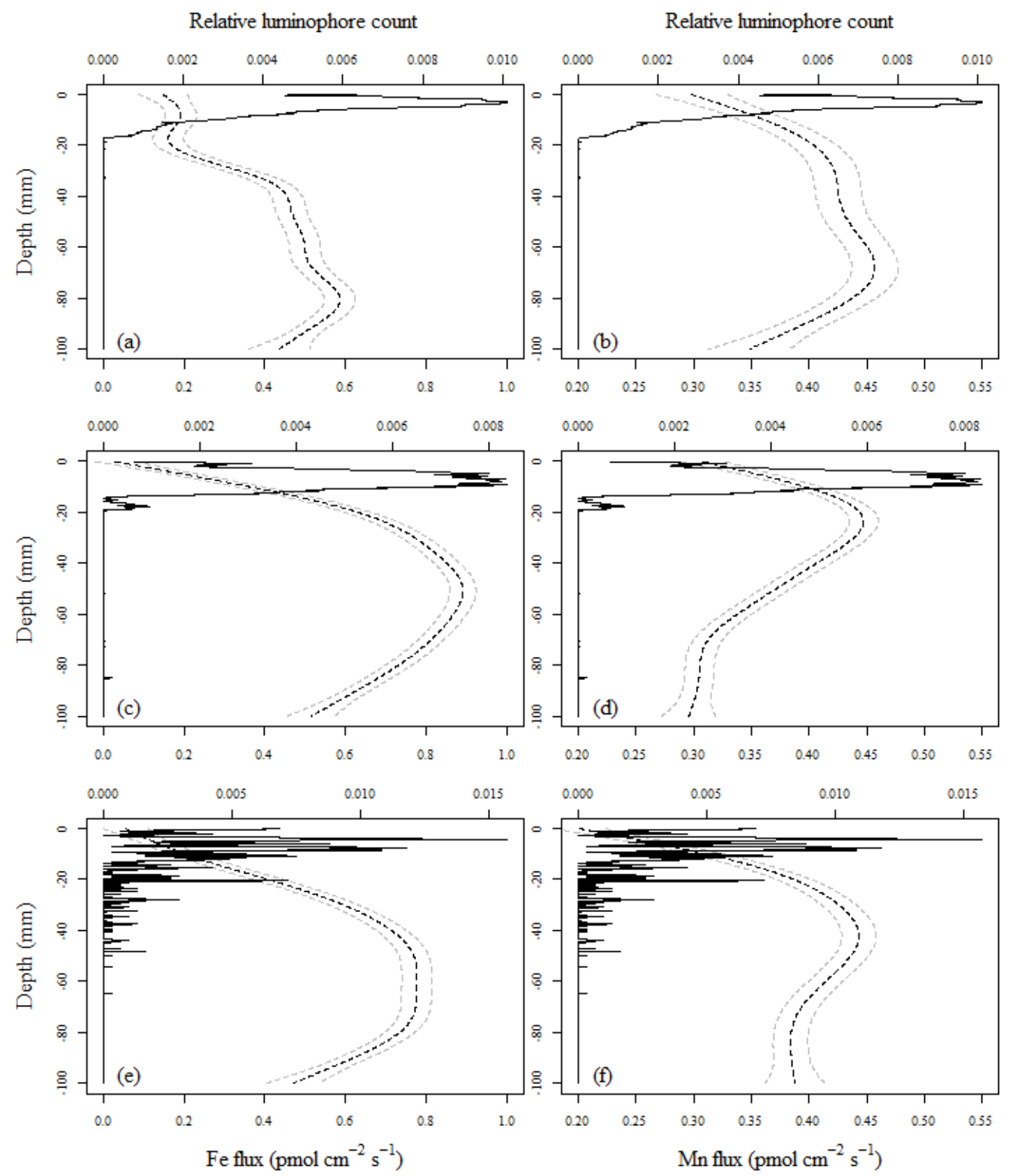

Fig. 4. Predicted trace metal profiles (dotted black lines) $\pm \mathrm{SE}$ (dotted grey lines) from fitted GAMs for Fe (a), (c), (e) and Mn (b), (d), (f) for deployments 1 (a), (b), 2 (c), (d) and 3 (e), (f). Solid black lines show luminophore profiles (relative counts) of the final fg-SPI image from each time-lapse sequence.

deployment 3 can be related to more intense bioturbation activity (Fig. 4c), which may have caused a downwards shift in the location of the peak concentrations of both $\mathrm{Mn}$ and $\mathrm{Fe}$, i.e. extended regions of $\mathrm{Fe}$ and $\mathrm{Mn}$ release. This view is supported by deployment 1 , where a more defined and sharper peak in $\mathrm{Fe}$ (Fig. 4a) reflects a less noisy luminophore profile and is associated with less active bioturbation and smaller mean particle displacements.

\section{Discussion}

Although the sediment mixing depth provides a good proxy of broad scale sediment function, integrating both biotic and abiotic processes (Teal et al., 2010), it is necessary to understand the intimate association between infaunal (e.g. bioturbation) and biogeochemical processes at the small scale before broader scale patterns and processes can be appreciated. For example, the paradigm of vertical zonation of biogeochemical reactions within the sediment are known to be 
perturbed by infaunal activities, creating a mosaic of oscillating redox microniches within the sediment (Aller, 1984; Zajac, 2001; Stief and de Beer, 2006; Volkenborn et al., 2012; Stahl et al., 2012). As stated previously, due to the particulate nature of the oxidants $\mathrm{Fe}$ and $\mathrm{Mn}$, bioturbation is considered a particularly important regulator of $\mathrm{Mn}$ and $\mathrm{Fe}$ reduction (Aller, 1994; Thamdrup et al., 1994). Recent studies have qualitatively linked the degree of the disruption of redox zones to infaunal activity levels (Bertics and Ziebis, 2009; Teal et al., 2009; Volkenborn et al., 2012) and it is clear that sediment microniches significantly contribute to the observed variability between trace metal profiles (Shuttleworth et al., 1999; Stockdale et al., 2009; Stahl et al., 2012).

Results obtained from this in situ study in Loch Creran, Scotland, show that the paradigm of the vertical zonation of biogeochemical zones (i.e. oxic, denitrification, $\mathrm{Mn}, \mathrm{Fe}$ and sulphate reduction zones) has been perturbed. Reduced forms of both $\mathrm{Fe}$ and $\mathrm{Mn}$ in sediment porewaters, from where the metals flux to and are bound within the DGT resin gel, are occurring at variable depths across a very small spatial scale $(\mathrm{mm})$. These patterns can be directly related to the spatiotemporal variability in bioturbation activity (mixing of sediment particles), which is supported by the SPI results showing vertical, horizontal and temporal variability in bioturbation activity within the sediment; these dynamics create a four-dimensional mosaic of environmental conditions. In addition to the one-dimensional progression of redox zones vertically downwards in the sediment, redox zonation also progresses radially away from burrows. As Mn oxides are particulate, bioturbation can convey Mn(III, IV) species downwards into the anoxic sediments where they are reduced and associated with a peak of dissolved Mn (Sundby, 2006; Mouret et al., 2008). Benthic organisms thus bring about a net flux of oxidised manganese away from the sedimentwater interface by mixing manganese-rich sediment with manganese-poor sediment across the concentration gradient. The same is true for Fe: diagenesis of Fe occurs similarly to that of manganese, although the cycle is more complex due to the variable reactivity of iron minerals (Sundby, 2006). Soluble iron can also be precipitated by sulfide during sulfate reduction (Sundby, 2006), which may hide the peak of dissolved $\mathrm{Fe}$ associated with Fe reduction from the DGT measurements (Teal et al., 2009). These results can be directly compared to findings in Teal et al. (2009), where a species poor community with low bioturbation activity shows a much more defined zonation and transition of $\mathrm{Mn}$ and Fe reduction zones, compared to a more diverse site (as in Loch Creran) with higher infaunal (as well as epifaunal in surface layers) activity which perturbs the definition of the zones.

Although the effects of bioturbation on nutrient cycling are well documented (e.g. Ieno et al., 2006; Stief and de Beer, 2006; Dunn et al., 2009), and are known to be influenced by many abiotic factors, the coupling of faunal behaviour and nutrient cycles has only recently been qualitatively achieved in laboratory (Stief and de Beer, 2006;
Gilbertson et al., 2012; Volkenborn et al., 2012) and in situ experiments (Volkenborn et al., 2007; Glud et al., 2009; Godbold and Solan, 2009; Teal et al., 2009, 2010). As demonstrated here, providing a direct quantitative link remains a challenge. The most striking feature of this study was the pronounced variation in both infaunal bioturbation activity and trace metal profiles, even at relatively short distances of a few $\mathrm{cm}$. The difficulty of determining the shape of sediment particle and porewater associated metal profiles highlights an intrinsic difficulty in investigating and quantifying organismprocess-function relations in a natural environment. Speciesenvironment interactions are context-dependent (Rossi et al., 2008) and thus relations within transient natural communities are extremely variable in both time and space. Even on small spatial scales (within a $50 \mathrm{~m}$ diameter study site) and with temporal averaging (over a 5 day period), it is clear that levels and types of bioturbation observed are largely dependent on the temporal dynamics of assemblage structure, presumably including changes in behaviour resulting from species interactions (Maire et al., 2010). Whilst this is not surprising, it is important to highlight that in most in situ studies of bioturbation the variability in faunal structure and environmental conditions are routinely ignored and average effects are reported that mask the effects of certain circumstances. Here, the use of imaging technology coupled with multiple environmental sensors meant that discrete bioturbation events (sensu Solan et al., 2004b) can be directly related to species-specific behaviour (i.e. locomotion by $C$. maenas, feeding by $T$. communis, burrowing by A. filiformis) and/or environmental conditions (e.g. ebb and flow of the tide, Solan and Kennedy, 2002). These observations underpin the parameter values of the bioturbation simulation model, as the highest activity and distances that particles are displaced will be strongly affected by such discrete events, yet previous work has underestimated their functional importance and structural role. It is clear, therefore, that extended and detailed observations are required to fully evaluate and integrate the modifying effects of tidal (Solan and Kennedy 2002, Biles et al. 2002) and day-night cycles (Rosenberg and Lundberg 2004), as well as the effects of intra- and inter-specific interactions (Ieno et al. 2006, Caliman et al. 2007) on net benthic process (bioturbation). Understanding how benthic process-function relations alter under specific circumstances is likely to provide insight into ecological consequences of anticipated environmental change (Bulling et al., 2010; Hicks et al., 2011).

The trace metal profiles reflect similarly high variability as the bioturbation activity. The presented "fluxes" are defined as the time-averaged flux of metal from the porewaters to the resin strip of the DGT gel. There are some limitations to interpreting the absolute values as these can only be interpreted quantitatively as pore-water $\mathrm{Fe}$ or Mn concentrations if the porewaters are effectively buffered by rapid resupply from a local source, such as a desorbing solid phase, or if there is no supply from solid phase to solution (Davison et al., 1997; Stockdale et al., 2009). In reality, quantitative interpretation 
is more complex as usually some solid phase resupply does occur (Fones et al., 2001; Stockdale et al., 2009). The DGT most accurately describes the flux of $\mathrm{Fe} / \mathrm{Mn}$ to the gel probe from the porewater, and hence the DGT probe interfacial metal concentration, and by proxy the comparative metal availability with depth or location. Although DET gels reflect better the actual porewater concentrations (Fones et al., 2001), deployment of DET together with the SPI is not feasible as the DET gels would re-equilibrate with the water during the recovery of the lander, In addition, analytical detection limits need to be a lot lower for DET without the benefit of metal pre-concentration that DGT provides. The general conclusion is that DGT measurements are best treated as an assessment of the solute that can be locally supplied in response to a perturbation. A local peak in the signal indicates a local elevation in the concentration in the porewaters or a locally increased supply from the solid phase (see review by Stockdale et al., 2009). In order to gain an insight into redox zones in the sediment, the shape of the profiles and the depth of the peaks in fluxes and metal couple relationships with depth, rather than the absolute concentrations of trace metals, are of interest and the DGT therefore functions well for the lander-type deployment used here. Vertical profiles of dissolved manganese in pore waters often display a concentration maximum immediately below the oxic front, with a downward directed gradient below the maximum. Despite the high degree of variability detected between replicate trace metal profiles, it was possible to fit smoothers that indicate a consistent underlying pattern of $\mathrm{Mn}$ reduction and $\mathrm{Fe}$ reduction zones across replicates, regardless of fundamental differences in the type and amount of bioturbation. However, the detail of the variation between deployments and linking these peaks with activity remains challenging despite the simultaneous collection of high-resolution data.

The difficulty of linking particle movement patterns and trace metal profiles maybe explained partly by the disconnect between the spatio-temporal scales over which particle movement and porewater bioirrigation operate (e.g. Berg et al., 2001). Whilst luminophore profiles take an extended time period (hours to days, e.g. Teal et al., 2008; Teal 2009) to establish a homogenous distribution within the most actively mixed sediment layer, trace metal profiles form more rapidly because they integrate changes in the sediment pore water concentrations that oscillate on much shorter timescales (e.g. Forster and Graf, 1995), immediately reacting to influxes of oxygenated water (Stief and de Beer, 2006; Wethey et al., 2008; Shull et al., 2009). Near the sediment-water interface of continental margin muds, diagenesis proceeds via a succession of transient states that reflects variable external forcing and involves a multitude of redox reactions whose relative importance can vary in time and space. The transient state can be difficult to observe directly with conventional techniques, and much of what is known comes from indirect evidence (Sundby, 2006). Bioturbation, or seasonal redox oscillations due to episodic organic matter sedimenta- tion are considered the major causes of short-term (daysmonths) transient porewater profiles (e.g. Aller, 1994; Anschutz et al., 2000), but porewater chemistry can thus also be affected by processes not considered here, in particular tidal currents at the large scale (Kuwae et al., 2003), bioirrigation at smaller scales (Waldbusser and Marinelli, 2006; Na et al., 2008; Shull et al., 2009; Volkenborn et al., 2012), the complexities surrounding metal resupply in porewaters (e.g. Peterson et al., 1996; Stockdale et al., 2009; Stahl et al., 2012), and also the frequency of deeper bioturbation activity.

Longer deployments of the fg-SPI would no doubt reduce the variability between the bioturbation model results as the longer the deployment, the more likely the SPI-camera is to pick up the full range of organisms in the community sampled and the less frequent deeper mixing events. For the DGT gels however, longer deployments may be a disadvantage as a limitation of $\mathrm{Fe}$ and Mn supply to the gels is more likely to occur. These differences in scales of observation between processes already linked in a complex manner is likely to remain a challenge for in situ studies into the future. Nevertheless, the fact that it is possible to detect underlying general patterns and links between bioturbation and $\mathrm{Fe}$ and $\mathrm{Mn}$ profiles in the presence of substantial variation and differences in the scales of modus operandi, suggests that with appropriate multidisciplinary collaboration the same can be achieved at larger scales despite perceived practical constraints (Raffaelli et al., 2005; Raffaelli, 2006; Benton et al., 2007). A balance should be found between understanding the fine details of sediment processes versus collecting measurements that can contribute to broader scale questions. Thus, the immediate challenge in understanding species-process-function-environment relations is to reconcile effects observed at small scale and under specific circumstances with the consistent and general effects that operate at larger temporal and spatial scales, associated with, for example, human impacts on the sediment (e.g. pollution, trawling) and environmental change.

\section{Supplementary material related to this article is available online at: http://www.biogeosciences.net/10/ 2365/2013/bg-10-2365-2013-supplement.zip.}

Acknowledgements. The authors acknowledge I. Ezzi and the crew of the R/V Seol Mara (SAMS), as well as M. Sayer and the divers of the NERC National Facility for Scientific Diving (NFSD). We are also grateful to A. Brown and N. Lyman (Cefas) and P. Bagley (Oceanlab) for engineering assistance, L. Murray and E. Hewitt for assistance in the field (Oceanlab), and G. Fones and S. Tierney for assistance with the ICP-MS (University of Portsmouth). Furthermore, we thank Jack Middelburg (Utrecht University), Fillip Meysman (Netherlands Institute of Sea Research) and three anonymous reviewers for valuable comments in improving the manuscript. This work was supported by a University of Aberdeen 
6th century scholarship (awarded to L. T.), CEFAS Lowestoft (DP204), NERC NFSD support (08/02) and a SAMS research bursary (awarded to L. T).

All time-lapse fg-SPI sequences are available online from: https://www.bodc.ac.uk/data/

Edited by: S. W. A. Naqvi

\section{References}

Aller, R. C.: The effects of macrobenthos on chemical properties of marine sediments and overlying water, in: Animal-sediment relations, the biogenic alteration of sediments, edited by: Call, P. L. and Tevesz, M. J. S., Plenum Press, New York, 53-102, 1982.

Aller, R. C.: The importance of relict burrow structures and burrow irrigation in controlling sedimentary solute distributions, Geochim. Cosmochim. Ac., 48, 1929-1934, 1984.

Aller, R. C.: Bioturbation and Manganese cycling in hemipelagic sediments, Phil. Trans. Roy. Soc. A, 331, 51-68., 1990.

Aller, R. C.: The sedimentary Mn cycle in Long Island Sound: Its role as intermediate oxidant and the influence of bioturbation, $\mathrm{O}_{2}$, and $\mathrm{C}_{\text {org }}$ flux on diagenetic reaction balances, J. Mar. Res., 52, 259-259., 1994.

Anschutz, P., Sundby, B., Lefrancois, L., Luther III., G. W., and Mucci, A.: Interactions between metal oxides and species of nitrogen and iodine in bioturbated sediments, Geochim. Cosmochim. Acta, 64, 2751-2763, 2000.

Benton, T. G., Solan, M., Travis, J. M. J., and Sait, S. M.: Microcosm experiments can inform global ecological problems, Trends Ecol. Evol., 22, 516-521, 2007.

Berg, P., Rysgaard, S., Funch, P., and Sejr, M. K.: Effects of bioturbation on solutes and solids in marine sediments, Mar. Ecol. Prog. Ser., 26, 81-94, 2001.

Bertics, V. J. and Ziebis, W.: Biodiversity of benthic microbial communities in bioturbated coastal sediments is controlled by geochemical microniches, ISME Journal, 3, 1269-1285, 2009.

Biles, C. L., Paterson, D. M., Ford, R. B., Solan, M., and Raffaelli, D. G.: Bioturbation, ecosystem functioning and community structure, Hydrol. Earth Syst. Sci., 6, 999-1005, 2002, http://www.hydrol-earth-syst-sci.net/6/999/2002/.

Bulling, M. T., Solan, M., Dyson, K. E., Hernandez-Milian, G., Luque, P., Pierce, G. J., Raffaelli, D., Paterson, D. M., and White, P. C. L.: Species effects on ecosystem processes are modified by faunal responses to habitat composition, Oecologia, 158, 511520, 2008.

Bulling, M. T., Hicks, N., Murray, L., Paterson, D. M., Raffaelli, D., White, P. C. L., and Solan, M.: Marine biodiversity-ecosystem functions under uncertain environmental futures, Phil. Trans. Roy. Soc. B, 365, 2107-2116., 2010.

Caliman, A., Leal, J. J. F., Esteves, F. A., Carneiro, L. S., Bozelli, R. L., and Farjalla, V. F.: Functional bioturbator diversity enhances benthic-pelagic processes and properties in experimental microcosms, J. N. Am. Benthol. Soc., 26, 450-459, 2007.

Cardinale, B. J., Srivastava, D. S., Duffy, J. E., Wright, J. P., Downing, A. L., Sankaran, M., and Jouseau, C.: Effects of biodiversity on the functioning of trophic groups and ecosystems, Nature, 443, 989-992, 2006.
Chapman, M. G. and Tolhurst T. J.: Relationships between benthic macrofauna and biogeochemical properties of sediments at different spatial scales and among different habitats in mangrove forests, J. Exp. Mar. Biol. Ecol., 343, 96-109, 2007.

Davison, W., Fones, G. R., and Grime, G. W.: Dissolved metals in surface sediment and a microbial mat at $100 \mu, \mathrm{m}$ resolution, Nature, 387, 886-888, 1997.

Davison, W., Fones, G. R., Harper, M., Teasdale, P., and Zhang, H.: Dialysis, DET and DGT: in situ diffusional techniques for studying water, sediments and soils, in: In situ monitoring of aquatic systems: chemical analysis and speciation, edited by: Buffle J. and Horvai G., IUPAC, Wiley, New York, NY, 496-569, 2000.

Duffy, J. E.: Why biodiversity is important to the functioning of real-world ecosystems, Front. Ecol. Environ., 7, 437-444, 2008.

Dunn, R. J. K., Welsh, D. T., Jordan, M. A., Teadale, P. R., and Lemckert, C. J.: Influence of natural amphipod (Vitoriopisa asutraliensis) (Chilton, 1923) population densities on benthic metabolism, nutrient fluxes, denitrification and DNRA in subtropical estuarine sediment, Hydrobiologia, 628, 95-109, 2009.

Duport, E., Stora, G., Tremblay, P., and Gilbert, F.: Effects of population density on the sediment mixing induced by the gallerydiffusor Hediste (Nereis) diversicolor, edited by: Müller, O. F., J. Exp. Mar. Biol. Ecol., 336, 33-41, 2006.

Dyson, K. E., Bulling, M. T., Solan, M., Hernandez-Milian, G., Raffaelli, D. G., White, P. C. L., and Paterson, D. M.: Influence of macrofaunal assemblages and environmental heterogeneity on microphytobenthic production in experimental systems, P. Roy. Soc. Lond. B, 274, 2547-2554, 2007.

Emmerson, M. C., Solan, M., Emes, C., Paterson, D. M., and Raffaelli, D.: Consistent patterns and the idiosyncratic effects of biodiversity in marine ecosystems, Nature, 411, 73-77, 2001.

Fan, Y., Zhu, Q., Aller, R. C., and Rhoads, D. C.: An in situ multispectral imaging system for planar optodes in sediments: examples of high-resolutions seasonal patterns of $\mathrm{pH}$, Aq. Geochem., 17, 457-471, 2011.

Fones, G. R., Davison, W., Holby, O., Jorgensen, B. B., and Thamdrup, B.: High-resolution metal gradients measured by in situ DGT/DET deployment in black sea sediments using an autonomous benthic lander, Limnol. Oceanogr. 46, 982-988, 2001.

Forster, S. and Graf, G.: Impact of irrigation on oxygen flux into the sediment: intermittent pumping by Callianassa subterranea and "piston-pumping" by Lanice conchilega, Mar. Biol., 123, 335346, 1995.

Germano, J. D., Rhoads, D. C., Valente, R. M., Carey, D. A., and Solan, M.: The use of Sediment Profile Imaging (SPI) for environmental impact assessments and monitoring studies: lessons learned from the past four decades, Oceanogr. Mar. Biol. Ann. Rev., 49, 235-298, 2011.

Gilbertson, W. W., Solan, M., and Prosser, J. I.: Differential effects of microbe-invertebrate interactions on benthic nitrogen cycling, FEMS Microbiol. Eco., 82, 11-22, 2012.

Glud, R. N., Tengberg, A., Kuhl, M., Kall, P. O. J., Klimant, I., and Host, G.: An in situ instrument for planar $\mathrm{O}_{2}$ optode measurements at benthic interfaces, Limnol. Oceanogr., 46, 2073-2080, 2001.

Glud, R. N., Thamdrup, B., Stahl, H., Wenzhoefer, F., Glud, A., Nomaki, H., Oguri, K., Revsbech, N. P., and Kitazato, H.: Nitrogen cycling in a deep ocean margin sediment (Sagami Bay, Japan), Limnol. Oceanogr., 54, 723-734, 2009. 
Godbold, J. A., and Solan, M.: Relative importance of biodiversity and the abiotic environment in mediating ecosystem process, Mar. Ecol. Prog. Ser., 396, 273-282, 2009.

Godbold, J. A., Bulling, M. B., and Solan, M.: Habitat structure mediates biodiversity effects on ecosystem properties, P. Roy. Soc. Lond. B Bio., 278, 2510-2518, 2011.

Halpern, B. S., Walbridge, S., Selkoe, K. A., Kappel, C. V., Micheli, F., D’Agrosa, C., Bruno, J. F., Casey, K. S., Ebert, C., Fox, H. E., Fujita, R., Heinemann, D., Lenihan, H. S., Madin, E. M. P., Perry, M. T., Selig, E. R., Spalding, M., Steneck, R., and Watson, R.: A global map of human impact on marine ecosystems, Science, 319, 948-952, 2008.

Hicks, N., Bulling M. T., Solan, M., Raffaelli, D., White, P. C. L., and Paterson, D. M.: Impact of biodiversity-climate futures on primary production and metabolism in a model benthic estuarine system, BMC Ecology, 11, 7, doi:10.1186/1472-6785-11-7, 2011.

Ieno, E. N., Solan, M., Batty, P., and Pierce, G. J.: How biodiversity affects ecosystem functioning: Roles of infaunal species richness, identity and density in the marine benthos, Mar. Ecol. Prog. Ser., 311, 263-271, 2006.

Jakobsson, M., Løvlie, R., Al-Hanbali, H., Arnold, E., Backman, J., and Mörth, M.: Manganese and color cycles in Arctic Ocean sediments constrain Pleistocene chronology, Geology, 28, 23-26, 2000.

Jamieson, A. J., Gebruk, A., Fujii, T., and Solan, M.: Functional effects of the hadal sea cucumber Elpidia atakama (Echinodermata: Holothuroidea, Elasipodia) reflect small-scale patterns of resource availability, Mar. Biol., 158, 2695-2703, 2011.

Kuwae, T., Kibe, E., and Nakamura, Y.: Effect of emersion and immersion on the porewater nutrient dynamics of an intertidal sandflat in Tokyo Bay, Estuar. Coast. Shelf Sci., 57, 929-940, 2003.

Lesven, L., Gao, Y., Billon, G., Leermakers, M., Ouddane, B., Fischer, J. C., and Baeyens, W.: Early diagenetic processes aspects controlling the mobility of dissolved trace metals in three riverine sediment columns, Sci. Tot. Environ., 407, 447-459, 2008.

Lyle, M.: The brown-green colour transition in marine sediments: A marker of the Fe(III)-Fe(II) redox boundary, Limnol. Oceanogr., 28, 1026-1033, 1983.

Maire, O., Duchene, J.-C., Bigot, L., and Greìmare, A.: Linking feeding activity and sediment reworking in the deposit-feeding bivalve Abra ovata with image analysis, laser telemetry, and luminophore tracers, Mar. Ecol. Prog. Ser., 351, 139-150, 2007.

Maire, O., Merchant, J. N., Bulling, M., Teal, L. R., Grémare, A., Duchêne, J. C., and Solan, M.: Indirect effects of non-lethal predation on bivalve activity and sediment reworking, J. Exp. Mar. Biol. Ecol., 395, 30-36, 2010.

Marinelli, R. L. and Williams, T. J.: Evidence for density-dependant effects of infauna on sediment biogeochemistry and benthicpelagic coupling in nearshore systems, Estuar. Coast. Shelf Sci., 57, 179-192, 2003.

Meysman, F. J. R. Malyuga, V. S., Boudreau, B. P., and Middelburg, J. J.: A generalized stochastic approach to particle dispersal in soils and sediments Geochim, Cosmochim. Acta, 72, 3460-3478, 2008.

Mouret, A., Anschutz, P., Lecroart, P., Chaillou, G., Hyacinthe, C., Deborde, J., Jorissen, F.J., Deflandre, B., Schmidt, S., and Jouanneau, J.-M.: Benthic geochemistry of manganese in the bay of Biscay, and sediment mass accumulation rate, Geo-Mar. Lett.,
29, 133-149, 2008.

Na, T., Gribsholt, B., Galaktionov, O. S., Lee, T., and Meysman, F. J. R.: Influence of advective bio-irrigation on carbon and nitrogen cycling in sandy sediments, J. Mar. Res., 66, 691-722, 2008.

Nogaro, G., Charles, F., Brage de Mendonça, Jr., J., MermillodBlondin, F., Stora, G., and François-Carcaillet, F.: Food supply impacts sediment reworking by Nereis diversicolor, Hydrobiologia, 598, 403-408, 2008.

Ouelette, D., Desrosiers, G., Gagne, J.-P., Gilbert, F., Poggiale, J. C., Blier, P. U., and Stora, G.: Effects of temperature on in vitro sediment reworking processes by a gallery biodiffusor, the polychaete Neanthes virens, Mar. Ecol. Prog. Ser., 266, 185-193, 2004.

Peterson, G. S., Ankley, G. T., and Leonard, E. N.: Effect of bioturbation on metal-sulfide oxidation in surficial freshwater sediments, Environ. Tox. Chem., 15, 2147-2155, 2009.

R Development Core Team: A Language and Environment for Statistical Computing, R Foundation for Statistical Computing, Vienna, Austria, available at http://www.R-project.org, 2008.

Raffaelli, D. G.: Biodiversity and ecosystem functioning: issues of scale and trophic complexity, Mar. Ecol. Prog. Ser. 311, 285294, 2006.

Raffaelli, D., Solan, M., and Webb, T. J.: Do marine ecologists do it differently?, Mar. Ecol. Prog. Ser., 304, 283-289, 2005.

Rhoads, D. C. and Cande, S.: Sediment profile camera for in situ study of organism-sediment relations, Limnol. Oceanogr., 16, 110-114, 1971.

Rosenberg, R. and Lundberg L.: Photoperiodic activity pattern in the brittle star Amphiura filiformis, Mar. Biol., 145, 651-656, 2004.

Rossi, F., Gribsholt, B., Middelburg, J. J., and Heip, C.: Contextdependent effects of suspension feeding on intertidal ecosystem functioning, Mar. Ecol. Prog. Ser., 354, 47-57, 2008.

Schiffers, K., Teal, L. R., Travis, J., and Solan, M.: Fitting a simulation model to highly resolved spatio-temporal bioturbation data, PLoS ONE, 6, e28028, doi:10.1371/journal.pone.0028028, 2011.

Shull, D. H., Benoit, J. M., Wojcik, C., and Senning J. R.: Infaunal burrow ventilation and pore-water transport in muddy sediments, Est. Coast. Shelf Sci., 83, 277-286, 2009.

Shuttleworth, S. M., Davison, W., and Hamilton-Taylor, J.: Twodimensional and fine structure in the concentrations of iron and manganese in sediment pore-waters, Environ. Sci. Technol., 33, 4169-4175, 1999.

Solan, M. and Kennedy, R.: Observation and quantification of insitu animal-sediment relations using time-lapse sediment profile imagery (t-SPI), Mar. Ecol. Prog. Ser., 228, 179-191, 2002.

Solan, M., Germano, J. D., Rhoads, D. C., Smith, C., Michaud, E., Parry, D., Wenzhofer, F., Kennedy, B., Henriques, C., Battle, E., Carey, D., Iocco, L., Valente, R., Watson, J., and Rosenberg, R.: Towards a greater understanding of pattern, scale and process in marine benthic systems: a picture is worth a thousand worms, J. Exp. Mar. Biol. Ecol., 285, 313-338, 2003.

Solan, M., Cardinale, B. J., Downing, A. L., Engelhardt, K. A. M., Ruesink, J. L., and Srivastaca, D. S.: Extinction and ecosystem function in the marine benthos, Science, 206, 1177-1180, 2004a.

Solan, M., Wigham, B. D., Hudson, I. R., Kennedy, R., Coulon, C. H., Norling, K., Nilsson, H. C., and Rosenberg, R.: In-situ quantification of bioturbation using time-lapse fluorescent sediment 
profile imaging (f-SPI), luminophore tracers and model simulation, Mar. Ecol. Prog. Ser., 271, 1-12, 2004b.

Stahl, H., Warnken, K. W., Sochaczewski, L., Glud, R. N., Davison, W., and Zhang, H.: A combined sensor for simultaneous high resolution 2D imaging of oxygen and trace metals fluxes, Limnol. Oceanogr. Meth., 10, 389-401, 2012.

Stief, P. and de Beer, D.: Probing the microenvironment of freshwater sediment macrofauna: Implications of deposit-feeding and bioirrigation for nitrogen cycling, Limnol. Oceanogr., 51, 25382548, 2006.

Stockdale, A., Davison, W., and Zhang, H.: Micro-scale biogeochemical heterogeneity in sediments: A review of available technology and observed evidence, Earth Sci. Rev., 92, 81-97, 2009.

Sundby, B.: Transient state diagenesis in continental margin muds, Mar. Cehm., 102, 2-12, 2006.

Teal, L. R.: The influence of infaunal bioturbation on ecosystem processes in the sediment mixed layer, $\mathrm{PhD}$ Thesis, University of Aberdeen, 2009.

Teal, L. R., Parker, E. R, Fones, G., and Solan, M.: Simultaneous determination of vertical transitions of colour, porewater metals and visualization of infaunal activity in marine sediments, Limnol. Oceanogr., 54, 1801-1810, 2009.

Teal, L. R., Parker, E. R., and Solan, M.: The sediment mixed layer as a proxy for measuring benthic ecosystem process and function, Mar. Ecol. Prog. Ser., 414, 27-40, 2010.

Thamdrup, B., Fossik, H., and Jørgensen, B. B.: Manganese, iron, and sulfur cycling in a coastal marine sediment, Aarhus Bay, Denmark, Geochim. Cosmochim. Acta 58, 5115-5129, 1994.

Volkenborn, N., Hedtkamp, S. I. C., van Beusekorn, J. E. E., and Reise, K.: Effects of bioturbation and bioirrigation by lugworms (Arenicola marina) on physical and chemical sediment properties and implications for intertidal habitat succession, Est. Coast. Shelf Sci., 74, 331-343, 2007.

Volkenborn, N., Polerecky, L., Wethey, D. S., DeWitt, T. H., and Woodin, S. A.: Hydraulic activities by ghost shrimp Neotrypaea californiensis induce oxic-anoxic oscillations in sediments, Mar. Ecol. Prog. Ser., 455, 141-156, 2012.

Waldbusser, G. G. and Marinelli, R. L.: Macrofaunal mediation of porewater advection: role of species function, species interaction, and kinetics, Mar. Ecol. Prog. Ser., 311, 217-231, 2006.
Webb, T. J., Aleffi, I. F., Amouroux, J. M., Bachelet, G., Degraer, S., Dounas, C., Fleischer, Dirk, Gremare, A., Herrmann, M., Hummel, H., Karakassis, I., Kedra, M., Kendall, M. A., Kotwicki, L., Labrune, C., Nevrova, E. L., Occhipinti-Ambrogi, A., Petrov, A., Revkov, N. K., Sarda, R., Simboura, N., Speybroeck, J., Van Hoey, G., Vincx, M., Whomersley, P., Willems, W., and Wlodarska-Kowalczuk, M.: Macroecology of the European soft sediment benthos: insights from the MacroBen database, Mar. Ecol. Prog. Ser., 382, 287-296, 2009.

Wethey, D. S., Woodin, S. A., Volkenborn, N., and Reise, K.: Porewater advection by hydraulic activities of lugworms, Arenicola marina: a field, laboratory and modelling study, J. Mar. Res., 66, 255-273, 2008.

Widdicombe, S. and Needham, H. R.: Impact of $\mathrm{CO}_{2}$-induced seawater acidification on the burrowing activity of Nereis virens and sediment nutrient flux, Mar. Ecol. Prog. Ser., 341, 111-122, 2007.

Wood, S. N.: Generalised additive modelling: An introduction in R, Chapman and Hall, 2006.

Worm, B., Barbier, E. B., Beaumont, N., Duffy, J. E., Folke, C., Halpern, B., Jackson. J. B. C, Lotze, H. K., Micheli, F., Palumbi, S. R., Sala, E., Selkoe, K. A., Stachowitz, J. J., and Watson, R.: Impacts of biodiversity loss on ocean ecosystem services, Science, 314, 787-790, 2006.

Zajac, R. N.: Organism-sediment relations at multiple spatial scales: implications for community structure and successional dynamics, in: Organism-Sediment Interactions, edited by: Aller, J. Y., Woodin, S. A., and Aller, R. C., University of South Carolina Press, Columbia, SC, 119-139, 2001.

Zhang, H. and Davison, W.: Performance characteristics of diffusion gradients in thin films for the in situ measurement of trace metals in aqueous solution, Anal. Chem., 67, 3391-3400, 1995.

Zhang, H., Davison, W., Miller, S., and Tych, W.: In situ high resolution measurements of fluxes of $\mathrm{Ni}, \mathrm{Cu}, \mathrm{Fe}$, and $\mathrm{Mn}$ and concentrations of $\mathrm{Zn}$ and $\mathrm{Cd}$ in porewaters by DGT, Geochim. Cosmochim. Acta, 59, 4181-4192, 1995.

Zhu, Q. and Aller, R. W.: Two-dimensional dissolved ferrous iron distributions in marine sediments as revealed by a novel planar optical sensor, Mar. Chemi., 136/137, 14-23, 2012. 